\title{
The Impact on Future Prescribing Patterns of Opioid Use Disorder (OUD) Education and Waiver Provision During Residency
}

\author{
Victoria Boggiano, MD, MPH, Courtenay Gilmore Wilson, PharmD, BCACP, CPP, \\ E. Blake Fagan, MD, Julienne Kirk, PharmD, Kelly Bossenbroek-Fedoriw, MD, and \\ Casey R. Tak, PhD, MPH
}

Background: Family medicine residency programs vary in the extent of training offered on opioid use disorder (OUD) in their curricula. The purpose of this study was to determine the impact of OUD education and buprenorphine waiver provision on postresidency buprenorphine prescribing patterns.

Methods: Three North Carolina family medicine residency programs differed in the extent to which they taught OUD, including buprenorphine waiver provision. Program A required OUD education and assisted residents in obtaining a waiver; Program B offered OUD education and did not assist with obtaining a waiver; and Program C did not offer OUD education. In November 2019, graduates from these 3 programs were surveyed regarding the extent to which they engaged in treatment of OUD. Descriptive statistics were used to characterize the survey participants and their responses.

Results: of the 62 graduates invited to participate, $49(79.0 \%)$ responded. Across the 3 programs, the percentage of graduates with a waiver varied significantly $(P<.0001)$ : Program $A(84.2 \%)$, Program B (33.3\%), and Program C (0.0\%). Of those who were not waivered, Program B had a larger percentage that desired to prescribe buprenorphine products $\mathbf{( 7 0 . 0 \% )}$ as compared with Program $C$ (9.1\%) $(P=.009)$.

Conclusions: Family medicine residency graduates from programs with more integrated oUD education were more likely to obtain and use a waiver to prescribe buprenorphine-containing medications postgraduation. (J Am Board Fam Med 2020;33:998-1003.)

Keywords: Buprenorphine, Family Medicine, Health Services Accessibility, Health Workforce, Opioid-Related Disorders, Primary Health Care, Residency, Surveys and Questionnaires

\section{Introduction}

The opioid crisis is a significant public health concern across the United States and health care providers should look for creative ways to address it. ${ }^{1}$ In 2018, 2 million Americans had a diagnosed opioid

This article was externally peer reviewed.

Submitted 8 April 2020; revised 3 June 2020; accepted 4 June 2020.

From the Department of Family Medicine, School of Medicine, The University of North Carolina at Chapel Hill, Chapel Hill (VB, CGW, EBF, KBF); UNC Health Sciences at MAHEC, Asheville, NC (CGW, EBF, CRT); Division of Practice Advancement and Clinical Education, Eshelman School of Pharmacy, The University of North Carolina at Chapel Hill, Chapel Hill (CGW); Department of Family and Community Medicine, Wake Forest School of Medicine, Winston-Salem, NC (JK); Division of Pharmaceutical Outcomes and Policy, Eshelman School of Pharmacy, The University of North Carolina at Chapel Hill, Chapel Hill, NC (CRT)

Funding: None.

Conflict of interest: None. use disorder (OUD) and more than 10 million Americans misused opioids. ${ }^{2}$ Medications for OUD (MOUDs) are the evidence-based, standard of care for treating OUD. ${ }^{3}$ They reduce morbidity and mortality and improve overall social functioning. ${ }^{1}$ Despite recent increases in access to MOUD, nearly half of all patients with an OUD do not receive pharmacotherapy. ${ }^{2}$ Office-based opioid treatment (OBOT) is the treatment of OUD in the primary care setting. ${ }^{4}$ Providers must complete additional training and be federally waivered, permissible through the Drug Addiction Treatment Act (DATA) 2000, to prescribe buprenorphine-containing medications. ${ }^{4}$ DATA 2000

Corresponding author: Courtenay Gilmore Wilson, PharmD, BCACP, CPP, 123 Hendersonville Rd, Asheville, NC 28803 (E-mail: courtenay.wilson@mahec.net). 
allows qualified health professionals to treat OUD with Scheduled III, IV, and V medications outside of the opioid treatment program setting. ${ }^{4}$ For family medicine physicians, this the mechanism to prescribe buprenorphine-containing medications, which is Schedule III, under the OBOT model.

Family medicine physicians are at the front lines of caring for individuals with OUD given their breadth of training and their longitudinal relationships with patients. The American Academy of Family Physicians has called on primary care providers to assume this role. ${ }^{5}$ Family physicians also develop meaningful relationships with entire family units, which can be helpful when treating individuals with OUD. ${ }^{6}$ Common barriers to OBOT include lack of knowledge, experience, and institutional support. ${ }^{7-10}$ In addition, many providers with their DATA 2000 waiver never prescribe buprenorphinecontaining medications. ${ }^{10}$ Residency training offers a unique opportunity to address these barriers.

We sought to determine the impact of varying levels of OUD education, including requiring DATA 2000 waiver training, in family medicine curricula on postgraduation prescribing of buprenorphine-containing medications.

\section{Methods}

\section{Population}

Sixty-two graduates from 3 family medicine residency programs in North Carolina were surveyed from November 2019 through January 2020 about treating OUD in their current practice. Participants were eligible to participate in the study if they graduated from 1 of 3 programs in 2017 or 2018.

For these graduating classes, the 3 programs' (A, $\mathrm{B}$, and $\mathrm{C}$ ) curricula varied in the extent of OUD education, which we defined as the opportunity to treat continuity patients with MOUD, didactic sessions focused on OUD, or elective experiences in OUD. Program A required OUD education and assisted residents in obtaining a DATA 2000 waiver during residency. Program B offered OUD education but did not assist residents in obtaining a DATA 2000 waiver. Residents could obtain their waiver after graduation. Program $\mathrm{C}$ did not provide OUD education and did not assist residents in obtaining a DATA 2000 waiver.

\section{Survey}

We emailed graduates of these programs a link to complete an online survey through Qualtrics
(Qualtrics, Provo, UT), a Web-based survey platform. The survey assessed OUD education during residency, possession of a DATA 2000 waiver, timing of DATA 2000 waiver acquisition, current MOUD prescribing practices, barriers to prescribing MOUD, desire for additional training around MOUDs, information about their current practice, and demographic information. Using a 7-point Likert scale, participants were also asked to determine the support of their current clinic on prescribing buprenorphine-containing medications. All invited participants were compensated with a $\$ 5$ gift card, regardless of survey completion.

\section{Statistical Approach}

Descriptive statistics were used to characterize the survey participants and their responses. $\chi^{2}$ or Fisher's Exact test and analysis of variance or Kruskal-Wallis tests, as appropriate, were used to determine categorical and continuous differences, respectively, in prescribing practices between the 3 programs' graduates. This study was reviewed and deemed exempt by The University of North Carolina at Chapel Hill Institutional Review Board. All data were analyzed in SAS v9.4 (SAS Institute, Cary, NC).

\section{Results}

Of the 62 eligible graduates, $49(79.0 \%)$ responded, and $48(77.4 \%)$ provided information about their residency program. The majority of respondents were female $(56.3 \%)$, a plurality worked in rural settings (40.4\%), and the mean age was 33 years old (Table 1). Of those that responded, 24 (50.0\%) reported having a DATA 2000 waiver, 19 (79.2\%) of whom had prescribed buprenorphine-containing medications and $16(66.7 \%)$ of whom had possessed the waiver for more than 2 years (Table 2). Of those who did not have a DATA 2000 waiver, 15 (62.5\%) indicated that they did not desire to prescribe buprenorphine-containing medications in the future.

When comparing the 3 programs, Program A had significantly more graduates who had a waiver than Program B $(85.0 \%$ vs $41.2 \% ; P=.0054)$ and across all 3 programs $(85.0 \%$ vs $41.2 \%$ vs $0.0 \%$, $P<.0001)$ (Table 2). Once waivered, both Program A and Program B graduates tended to engage in prescribing buprenorphine-containing medications: Program A, 88.2\%; and Program B, 57.1\% $(P=.12)$. Among those who were not waivered, Program B had a larger percentage who desired to prescribe buprenorphine-containing medications $(70.0 \%)$ as 
Table 1. Demographic and Practice Characteristics of Residency Graduates

\begin{tabular}{lc}
\hline Characteristic & Response (n = 48) \\
\hline Female, n (\%) & $27(56.3)$ \\
Age in years (SD) & $33.1(2.5)$ \\
Years in clinical practice, n (\%) & \\
$<2$ years & $24(50.0)$ \\
$\geq 2$ years & $24(50.0)$ \\
Residency program matriculation, n (\%) & \\
Program A & $20(41.7)$ \\
Program B & $17(35.4)$ \\
Program C & $11(22.9)$ \\
Location of current clinical practice (\%) & \\
Urban & $11(23.4)$ \\
Suburban & $17(36.2)$ \\
Rural & $19(40.4)$ \\
Unreported & $1(0.0)$ \\
Setting of current clinical practice (\%) & \\
FQHC & $11(22.9)$ \\
RHC & $2(4.2)$ \\
Private practice & $8(16.7)$ \\
Academic setting & $11(22.9)$ \\
Hospitalist/urgent care & $4(8.3)$ \\
Other & $12(25.0)$ \\
Does your practice see a substantial number & \\
of uninsured patients? (\%) & \\
Yes & $28(59.6)$ \\
No & $19(40.4)$ \\
Unreported & $1(0.0)$ \\
\hline
\end{tabular}

FQHC, federally qualified health center; RHC, rural health clinic; SD, standard deviation.

compared with Program C (9.1\%) $(P=.009)$. The most common barriers to prescribing buprenorphine-containing medications among those not waivered were lack of behavioral health support (54.2\%), time constraints $(50.0 \%)$, and diversion/misuse concerns $(45.8 \%)$.

Graduates from all 3 programs indicated similar support for more MOUD training for family medicine physicians (Table 2), although graduates differed on whether they thought this training should happen in residency, in practice, or both. Graduates from Programs A and B have greater support for prescribing buprenorphine-containing medications in their current practices (mean, 2.31; SD, 1.8; and mean, 3.13; SD, 2.0, respectively) as compared with graduates from Program C (mean, 4.4; SD, 1.7) $(P=.001)$ (Table 3$)$. The most commonly available support personnel were a behavioral health specialist $(70.8 \%)$ and a pharmacist (54.2\%). Only $8.3 \%$ of physicians surveyed reported having access to a board-certified addiction specialist.

\section{Discussion}

Given the extent of the current opioid crisis, family physicians need knowledge and experience to care for patients with an OUD. Studies have shown that early-career family physicians are leading this charge. ${ }^{11}$ While some have advocated for requiring DATA 2000 waiver training during residency, it is not currently an ACGME requirement. ${ }^{12-13}$ The American Academy of Family Physicians recommended curriculum guidelines for substance use disorders include treating patients with buprenorphine; however, they do not call for residents to obtain their waivers to prescribe it. ${ }^{14}$

Although resident physicians desire training in MOUD, few programs offer it. ${ }^{15-17}$ Primary care residencies across the country have begun to implement OUD training with good success, yet the percentage of graduates who ultimately prescribe buprenorphine-containing medications are low. ${ }^{18} \mathrm{~A}$ 2016 survey, demonstrated that only $10 \%$ of early career family physicians felt prepared to prescribe buprenorphine-containing medications and only $7 \%$ of respondents were actively prescribing. ${ }^{19} \mathrm{~A}$ 2013 survey showed that nearly $80 \%$ of family medicine trainees treated patients with OUD during residency, but less than $20 \%$ of programs encouraged or required residents to obtain a DATA 2000 waiver. ${ }^{16}$ A 2012 survey of psychiatrists showed that those who received training during residency had more favorable views toward OBOT and identified fewer barriers to OBOT. ${ }^{20}$ However, post-hoc analysis showed that buprenorphine prescribing during residency was not associated with prescribing postgraduation. ${ }^{20}$

The findings from our survey correlate with what is understood about curricular design: namely, that offering increasingly complex interaction with a new skill, in this case, MOUD, increases confidence and competence. ${ }^{21}$ Our findings highlight that a more comprehensive program, where waiver training and active prescribing during residency is an expectation, yields more graduates who are actively prescribing buprenorphine-containing MOUDs. Interestingly, Program A and Program B had similar percentages of graduates who used their waiver when they had one, suggesting that offering 
Table 2. Comparison of Buprenorphine-Prescribing Practices and Training Needs Across the Graduates of the Three Residency Programs

\begin{tabular}{|c|c|c|c|c|c|}
\hline \multirow[b]{2}{*}{ Variable } & \multicolumn{3}{|c|}{ Residency Program } & \multirow{2}{*}{$\begin{array}{c}\text { Total } \\
(\mathrm{n}=48)\end{array}$} & \multirow[b]{2}{*}{$P$-Value } \\
\hline & $\mathrm{A}(\mathrm{n}=20)$ & $\mathrm{B}(\mathrm{n}=17)$ & $C(\mathrm{n}=11)$ & & \\
\hline \multicolumn{5}{|c|}{ Do you have a waiver? $\mathrm{n}(\%)$} & \multirow[t]{2}{*}{$<.0001$} \\
\hline Yes & $17(85.0)$ & $7(41.2)$ & $0(0)$ & $24(50)$ & \\
\hline \multicolumn{5}{|c|}{ If you do not have a waiver, do you want to prescribe buprenorphine-containing medications? n (\%) } & \multirow[t]{2}{*}{.01} \\
\hline Yes & $1(33.3)$ & $7(70.0)$ & $1(9.1)$ & $9(37.5)^{*}$ & \\
\hline \multicolumn{5}{|c|}{ If you do have a waiver, have you ever prescribed buprenorphine-containing medications? $\mathrm{n}(\%)$} & \multirow[t]{2}{*}{.13} \\
\hline Yes & $15(88.2)$ & $4(57.1)$ & N/A & $19(79.2)^{\dagger}$ & \\
\hline \multicolumn{5}{|c|}{ Is waiver training helpful, prohibitive, or neither? n (\%) } & \multirow[t]{4}{*}{.02} \\
\hline Helpful & $14(70.0)$ & $12(70.6)$ & $4(36.4)$ & $30(62.5)$ & \\
\hline Prohibitive & $3(15.0)$ & $3(17.7)$ & $0(0)$ & $6(12.5)$ & \\
\hline Neither & $3(15.0)$ & $2(11.8)$ & $7(63.6)$ & $12(25.0)$ & \\
\hline \multicolumn{5}{|c|}{ Do you want more training on opioid use disorder? n (\%) } & \multirow[t]{2}{*}{.58} \\
\hline Yes & $16(80.0)$ & $15(88.2)$ & $8(72.7)$ & $39(81.3)$ & \\
\hline \multicolumn{5}{|c|}{ Do you want more training in residency, practice, both, none? $\mathrm{n}(\%)$} & \multirow[t]{5}{*}{.03} \\
\hline Residency & $3(15.0)$ & $7(41.2)$ & $1(9.1)$ & $11(22.9)$ & \\
\hline Practice & $9(45.0)$ & $1(45.9)$ & $1(9.1)$ & $11(22.9)$ & \\
\hline Both & $4(20.0)$ & $7(41.2)$ & $6(54.6)$ & $17(35.4)$ & \\
\hline None & $4(20.0)$ & $2(11.8)$ & $3(27.3)$ & $9(18.8)$ & \\
\hline
\end{tabular}

${ }^{*} \mathrm{n}=25 ;{ }^{\dagger} \mathrm{n}=24$.

MOUD education to those who are interested may be a reasonable approach for some programs.

Waivering all residents could be a large financial investment, thus it may not be feasible at institutions with large residency programs. In this case, providing some exposure still increases the interest in future prescribing, as seen by the higher level of interest of nonwaivered graduates in Programs B compared with Program C. Our study mirrored other findings in that most graduates

Table 3. Clinic Resources and Environment for Office-Based Opioid Treatment

\begin{tabular}{|c|c|c|c|c|c|}
\hline \multirow[b]{2}{*}{ Variable } & \multicolumn{3}{|c|}{ Residency Program } & \multirow[b]{2}{*}{ Total $(\mathrm{n}=48)$} & \multirow[b]{2}{*}{$P$-Value } \\
\hline & $\mathrm{A}(\mathrm{n}=20)$ & $B(n=17)$ & $\mathrm{C}(\mathrm{n}=11)$ & & \\
\hline \multicolumn{5}{|c|}{ Please check if you have access to the following in your current practice $\mathrm{n}(\%)$} & N/A \\
\hline Licensed clinical addiction specialist & $6(30.0)$ & $2(11.8)$ & $1(9.1)$ & $9(18.8)$ & \\
\hline Board-certified addiction specialist & $1(5.0)$ & $3(17.7)$ & $0(0.0)$ & $4(8.3)$ & \\
\hline Behavioral health specialist & $16(80.0)$ & $12(70.6)$ & $6(54.6)$ & $34(70.8)$ & \\
\hline Peer support specialist & $6(30.0)$ & $2(11.8)$ & $0(0.0)$ & $8(16.7)$ & \\
\hline Pharmacist & $14(70.0)$ & $9(52.9)$ & $3(27.3)$ & $26(54.2)$ & \\
\hline \multicolumn{5}{|c|}{ My practice supports OBOT (7-point Likert scale; 1 = strongly agree; 7 = strongly disagree) $\mathrm{n}(\%)$} & 0.10 \\
\hline Agree & $15(75.0)$ & $11(64.7)$ & $4(36.4)$ & $30(62.5)$ & \\
\hline Neutral or disagree & $5(25.0)$ & $6(35.3)$ & $7(63.6)$ & $18(37.5)$ & \\
\hline Mean (SD) & $2.31(1.8)$ & $3.13(2.0)$ & $4.36(1.7)$ & $3.06(2.0)$ & 0.01 \\
\hline \multicolumn{5}{|c|}{ Do other providers in your practice setting prescribe buprenorphine-containing medications? n (\%) } & 0.02 \\
\hline Yes & $14(70.0)$ & $8(47.1)$ & $2(18.2)$ & $24(50.0)$ & \\
\hline No & $6(30.0)$ & $8(47.1)$ & $9(81.8)$ & $23(47.9)$ & \\
\hline Maybe/I don't know & $0(0.0)$ & $1(5.9)$ & $0(0)$ & $1(2.1)$ & \\
\hline
\end{tabular}

OBOT, office-based opioid treatment; SD, standard deviation. 
desired more MOUD training during residency or practice. ${ }^{15,20}$ Thus, programs could market the significant integration of OUD education in their curriculum as a recruitment tool.

There are several limitations to our study. First, our sample size was small thus there may be resident perspectives that are not captured here. However, these respondents do represent a diversity of training experiences and our response rate was high at $79.0 \%$. The second limitation is that there are many factors that influence physicians' comfort with new skills such as prescribing MOUD. Exposure during residency is just 1 of these factors, though we know that physicians are highly influenced by what they are exposed to during their training and that learning new skills after residency is more difficult.

\section{Conclusions}

Family medicine residency curricula that integrate OUD education increase the number of graduates who treat patients with OUD in their early careers. As the opioid crisis continues, health policy decision makers and programs directors should consider that earlier and greater exposure to OUD training during residency may lead to a greater supply of the MOUD-prescribing workforce.

To see this article online, please go to: http://jabfm.org/content/ 33/6/998.full.

\section{References}

1. National Academies of Sciences, Engineering, and Medicine. Medications for Opioid Use Disorder Save Lives. Washington, DC: The National Academies Press. 2019. Available from: http://nap.edu/25310.

2. Substance Abuse and Mental Health Services Administration. Key substance use and mental health indicators in the United States: Results from the 2018 National Survey on Drug Use and Health (HHS Publication No. PEP19-5068, NSDUH Series H-54). 2019. Rockville, MD: Center for Behavioral Health Statistics and Quality, Substance Abuse and Mental Health Services Administration. https://www.samhsa.gov/data/.

3. Crotty K, Freedman KI, Kampman KM. Executive summary of the focused update of the ASAM national practice guideline for the treatment of opioid use disorder. J Addict Med 2020;14:99-112.

4. Substance Abuse and Mental Health Services Administration. Medications for opioid use disorder. treatment improvement protocol (TIP) series 63, full document. HHS publication No.
(SMA) 18- 5063FULLDOC. Rockville, MD: Substance Abuse and Mental Health Services Administration, 2018.

5. Hauk L. Management of Chronic pain and opioid misuse: a position paper from the AAFP. Am Fam Physician 2017;95:458-9.

6. Center for Substance Abuse Treatment. Substance abuse treatment and family therapy. Chapter 1 . Available from: https:/www.ncbi.nlm.nih.gov/books/ NBK64269/. Accessed June 2, 2020.

7. DeFlavio JR, Rolin SA, Nordstrom BR, Kazal LA. Jr. Analysis of barriers to adoption of buprenorphine maintenance therapy by family physicians. Rural Remote Health 2015;15:3019.

8. Hutchinson E, Catlin M, Andrilla CH, Baldwin LM, Rosenblatt RA. Barriers to primary care physicians prescribing buprenorphine. Ann Fam Med 2014;12:128-33.

9. Walley AY, Alperen JK, Cheng DM, et al. Officebased management of opioid dependence with buprenorphine: clinical practices and barriers. J Gen Intern Med 2008;23:1393-8.

10. Andrilla CHA, Coulthard C, Larson EH. Barriers rural physicians face prescribing buprenorphine for opioid use disorder. Ann Fam Med 2017;15: 359-62.

11. Peterson LE, Morgan ZL, Eden AR. Early-career and graduating physicians more likely to prescribe buprenorphine. J Am Board Fam Med 2020;33:7-8.

12. Morris NP, Bentzley BS. Requiring buprenorphine waivers for psychiatry residents. Acad Psychiatry 2019;43:131-4.

13. Accreditation Council of Graduate Medical Education: ACGME program requirements for graduate medical education in family medicine. Available from: https://www.acgme.org/Portals/0/PFAssets/ ProgramRequirements/120_FamilyMedicine_2019. pdf?ver=2019-06-13-073936-407. Accessed March $31,2020$.

14. American Academy of Family Physicians. Recommended curriculum guidelines for family medicine residents: substance use disorders. AAFP Reprint No. 277. Available from: https://www.aafp.org/dam/ AAFP/documents/medical_education_residency/ program_directors/Reprint277_Substance.pdf. Accessed March 31, 2020.

15. James JR, Gordon LM, Klein JW, Merrill JO, Tsui JI. Interest in prescribing buprenorphine among resident and attending physicians at an urban teaching clinic. Subst Abus 2019;40:11-3.

16. Tesema L, Marshall J, Hathaway R, et al. Training in office-based opioid treatment with buprenorphine in US residency programs: a national survey of residency program directors. Subst Abus 2018;39: 434-40.

17. Tong S, Sabo R, Aycock R, et al. Assessment of addiction medicine training in family medicine 
residency programs: a CERA study. Fam Med 2017;49:537-43.

18. Kunins HV, Sohler NL, Giovanniello A, Thompson D, Cunningham CO. A buprenorphine education and training program for primary care residents: implementation and evaluation. Subst Abus 2013;34: 242-7.

19. Tong ST, Hochheimer CJ, Peterson LE, Krist AH. Buprenorphine provision by early career family physicians. Ann Fam Med 2018;16:443-6.
20. Suzuki J, Connery HS, Ellison TV, Renner JA. Preliminary survey of office-based opioid treatment practices and attitudes among psychiatrists never receiving buprenorphine training to those who received training during residency. Am J Addict 2014;23:618-22.

21. Tuxworth E. Competence based education and training: background and origins. In: Burke J, ed. Competency based education and trainig. London, UK: Routledge; 2005:18-31. 